\title{
Green Technology Approaches to Solid Waste Management in the Developing Economies
}

\author{
T. B. Hammed and M. K. C. Sridhar
}

\section{Contents}

Introduction

Green Technology Approach to Waste Management and Climate Change Mitigation

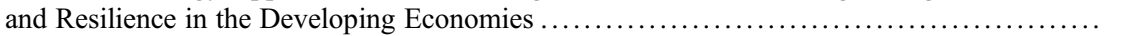

Field-Oriented Activities at Renewable Resource Centre, University of Ibadan ............ 5

Activities and Climate Change Adaptive Technologies at Various Sections of the Center ... 7

From Climate Change to Community Change: Lesson from Kube-Atenda, Nigeria ......... 12

Integrating Waste Picking at Dumpsites into a Value-Added Chain in Nigeria .............. 13

Waste-Picking Activities at the Dumpsites: A Case Study of Ibadan, Nigeria ........... 14

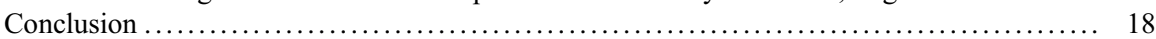

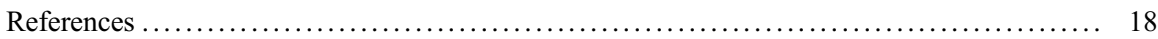

\section{Abstract}

The severity of extreme weather and climate change impacts around the world has been a public health concern in the last few decades. Apart from greenhouse gas generation, poor waste management exacerbates consequences of global warming such as flooding, lower crop yields, and the epidemic of diseases which can escalate into disastrous situations. The general public in developing economies sees wastes as valueless materials and disposes them through open burning, stream dumping, or as conveniently as possible. Also, the cutting of trees for firewood leads to deforestation and desertification that increase people's vulnerability to climate change impact. Against this backdrop, there is a need for a paradigm shift toward developing indigenous technologies that convert solid waste to cheap and clean energy. Various innovations use the "green technology approach" in putting trash back into the value chain. Furthermore, the green technology approach has a great potential to enhance adaptation and resilience among climate change-displaced populations where they can set up

T. B. Hammed $(\bowtie) \cdot$ M. K. C. Sridhar

Department of Environmental Health Sciences, Faculty of Public Health, College of Medicine,

University of Ibadan, Ibadan, Nigeria 
microenterprise on useful end products. In this chapter, unique features of these technologies at the Renewable Resources Centre of the University of Ibadan, practice-oriented researches, and a case study at Kube-Atenda community Ibadan, Nigeria, are presented. This chapter is therefore set out to showcase examples of waste management initiatives and strategies that have been successfully implemented elsewhere by the authors. It also focuses on how some countries in the continent, with developing economies, may foster their resilience and their capacity to adapt to climate change.

\section{Keywords}

Climate change $\cdot$ Waste management $\cdot$ Greenhouse gas $\cdot$ Indigenous technologies $\cdot$ Gaseous emission $\cdot$ Value chain

\section{Introduction}

Africa continent is at the forefront of vulnerability to global climate change within the world. The overall public in this continent sees wastes as valueless materials and disposes them through open burning, stream dumping, or as conveniently as possible (Hammed et al. 2018). Healthcare wastes are burnt in low-temperature incinerators with gaseous emissions. Also, the cutting of trees for firewood ends up in deforestation and desertification that increase people's vulnerability to temperature change impact. As an example, many households in Nigeria (up to 70\%), including households in rural areas (86\%), and households in urban areas (42\%), depend on solid fuel as their primary source of energy (Sridhar et al. 2016). The majority of the families that use solid fuel for cooking (94\%) operate open fire or stoves that have no chimneys or hood (Gwatkin et al. 2000). Other than climate change, the utilization of firewood as fuel for cooking exposes people, and most children and women, to smoke which poses a health risk to them and might cause respiratory illnesses (Salvi and Barnes 2010; Oluwole et al. 2012). Consistent with some researchers (Smith et al. 2001; Dehoust et al. 2005), the waste management sector makes a relatively minor contribution to greenhouse gas (GHG) emissions at a global scale, estimated at approximately $3-5 \%$ of total anthropogenic emissions in 2005 . Also, the average annual per capita waste generation in developing nations is estimated at $10-20 \%$ of that of developed countries, which is rising in response to economic growth. The waste sector is, however, in an exceedingly unique position to maneuver from being a secondary source of world emissions to becoming a major saver of emissions. It is on this premise that the Chief Director of the United Nations Environment Programme (UNEP) has been developing a technique for cobenefits of waste management within the context of global climate change. Integrated Solid Waste Management (ISWM) based on the 4Rs (reduce, recycle, reuse, and recovery) approach, with a special focus on sustainable consumption and production, E-waste management, conversion of agricultural biomass and waste plastics into 
energy and material resources, and management of hazardous waste, is being considered by the UNEP (UNEP 2010).

A recent report by Oyelaran-Oyeyinka of the UN Human Settlements Programme (UN-Habitat) (The Guardian, 27 April 2015) indicated that "African cities are the engines of wealth creation and therefore the centers of manufacturing, production, and innovation." This fact has not yet been justified and, as such, many cities have changed to slums that are characterized with incessant poverty, homelessness, the prevalence of preventable diseases, environmental pollution, maternal and child mortality, and other problems. These problems are further aggravated by social, economic, and environmental issues posed by climate change. There is, therefore, a need to strategize how African nations may foster their resilience and adaptation to the implication of climate change. Moreover, UNEP has identified two categories of solid waste management techniques that can reduce GHG emissions or contribute a net benefit to the development (UNEP 2010). The first set of technologies in view is technologically simple, locally available, and relatively cheap. The other set involves sophisticated, expensive technology and typically requires over 5 years to implement due to some factors, including financing, planning, and regulatory processes. The first process is seen to be very useful to strengthen resilience and adaptive capacities to counteract climate-related hazards within the developing economies. This chapter showcases samples of successful waste management initiatives and strategies that have been successfully implemented at the grassroots to build the capacity of the rural and urban dwellers, and foster their resilience to the menace of climate change.

\section{Green Technology Approach to Waste Management and Climate Change Mitigation and Resilience in the Developing Economies}

The significant problems of solid waste management in low-economic settings include lack of interaction and collaboration between stakeholders (community members, researchers, industrialists, and policymakers) in the policies that deal with waste. Also, there is a lack of political will for a waste-recycling program, no provision for research funds, unavailability of sustainable technologies and overdependence on imported technology, and lack of transparency and marketplace for recycled products. There is usually no sense of belonging in utilizing any project in which the end-users are not involved and motivated (McDonald and Ball 1998; Tucker et al. 1998; Paula and Elizabeth 2008; Fauzul and Viradin 2011; Hammed et al. 2012). Consequently, waste disposal systems do not conform to best practices, and in most cases, there is no sound or acceptable disposal method for solid waste in place. These wastes are usually heaped in piles within residential areas and oftentimes burnt once they overflow, or the stench from them becomes unbearable, creating air pollution-associated issues. The disposal and treatment of wastes lead to GHG emissions with severe global climate change impacts. Methane is the most significant GHG gas emanated from solid waste in the landfills, which is released during the breakdown of deposited organic matter (IPCC 2006). 
The gross of socioeconomic, environmental, and health difficulties the climate change phenomenon brings to the human being is depletion of natural resources, atmospheric pollution, outbreaks of vector-borne diseases, and flooding as well as crop failures that lead to malnutrition. Ironically, these impacts are mostly strongly seen and felt in developing countries, whose contributions to GHG emissions are far lower than their counterparts in the industrialized world. The aforementioned has called for effective initiatives and strategies such as those that supply renewable power from waste, mitigate climate change, create job opportunities, and promote growth in Gross Domestic Product (GDP) through wealth generation mechanisms. Generally, the benefits of green technology approach in the form of 5Rs (reduce, reuse, recycle, recover, and repair) to waste management include:

- Conservation of natural resources

- Environmental sanitation and protection from soil erosion, gully problems, deforestation, and desertification as trees are not cut

- Prevention of biodiversity loss

- Reduction of demand for landfilling of wastes

- Job creation and poverty eradication in the state; create wealth among peasant farmers

- Food security in the country through organic fertilizer production

- Promotion of local technology for sustainable development

- Reduce the amount of $\mathrm{CO}_{2}$ and methane gas being released into the atmosphere

- Saves foreign exchange for the nation

Considering the hierarchy of sustainable waste management, waste prevention is generally far better than any other waste management practice. That is, waste prevention eliminates greenhouse emissions and other environmental problems that are resulted from waste disposal and also ensures fewer resource extractions and manufacturing (the United States Environmental Protection Agency 2006). Following waste prevention, in terms of benefit, is waste recycling which may be a closed-loop or open-loop process. The open-loop recycling process occurs when recycled material is employed to form a completely new item. During this case, there is a loss of fabric quality which is brought up as "down-cycling." Another strategy being employed in line with waste recycling is industrial symbiosis. Here, industries exchange useful by-products among themselves (Ashton et al. 2009). Sometimes, the industries involved in this arrangement may form "recycling clusters" to facilitate the sharing of resources (Chertow and Lombardi 2005; Harris 1999). A good example is the United kingdom's National Industrial Symbiosis Programme that has successfully saved more than five million metric tons of wastes that could have ended in landfills and eliminated more than five million metric tons of GHG emissions since 2005 (Chertow 2009). The above state of affairs illustrates the necessity for identification of processes, methods, and tools which may help African nations from international best practices. This approach calls for global thinking and local action. 


\section{Field-Oriented Activities at Renewable Resource Centre, University of Ibadan}

The Renewable Resource Centre (RRC), located in the poultry unit of the Teaching and Research Farm, University of Ibadan, Nigeria (Fig. 1), was established in the year 2013. The center started with a few viable technologies developed in the Department of Environmental Health Sciences of the University which were scaled up in the field at several locations nationwide. The techniques are now proven to be viable to exploit commercially. The RRC has several sections, which are shown in Fig. 2:

(i) A building with training facilities to train up to 30 trainees, a storeroom, a research exhibition area (TECH park) to display environmental health research outputs, a caretaker's restroom, two toilets for visitors, a wellequipped mushroom spawn production area, and a small lounge where a visitor can sit and relax.

(ii) Biogas digesters to generate biogas from poultry piggery and cattle wastes for lighting and compression into cylinders.

(iii) A mushroom cultivation hut with thatched roof and bamboos, and accessories to produce on a large scale.

(iv) Liquid fertilizer production from biogas-spent slurry.

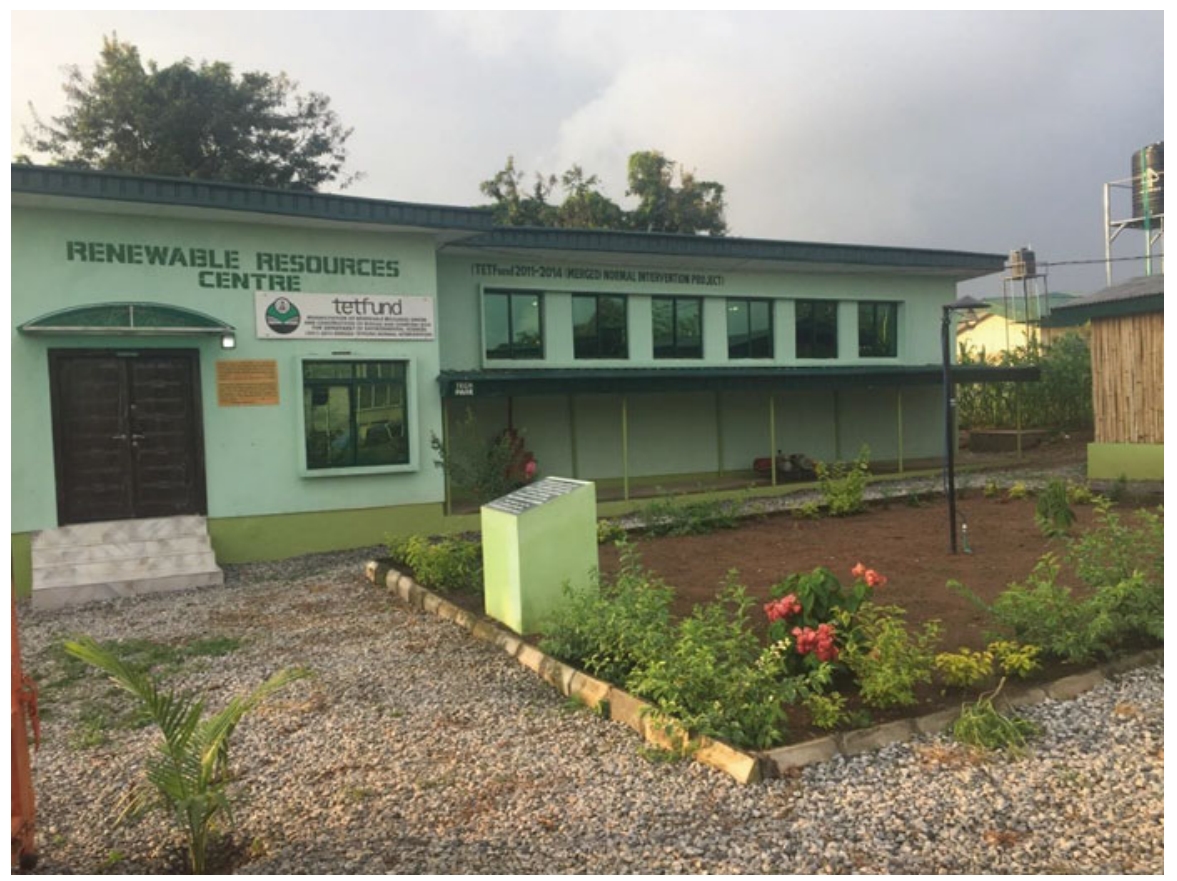

Fig. 1 The RRC main building in the university 


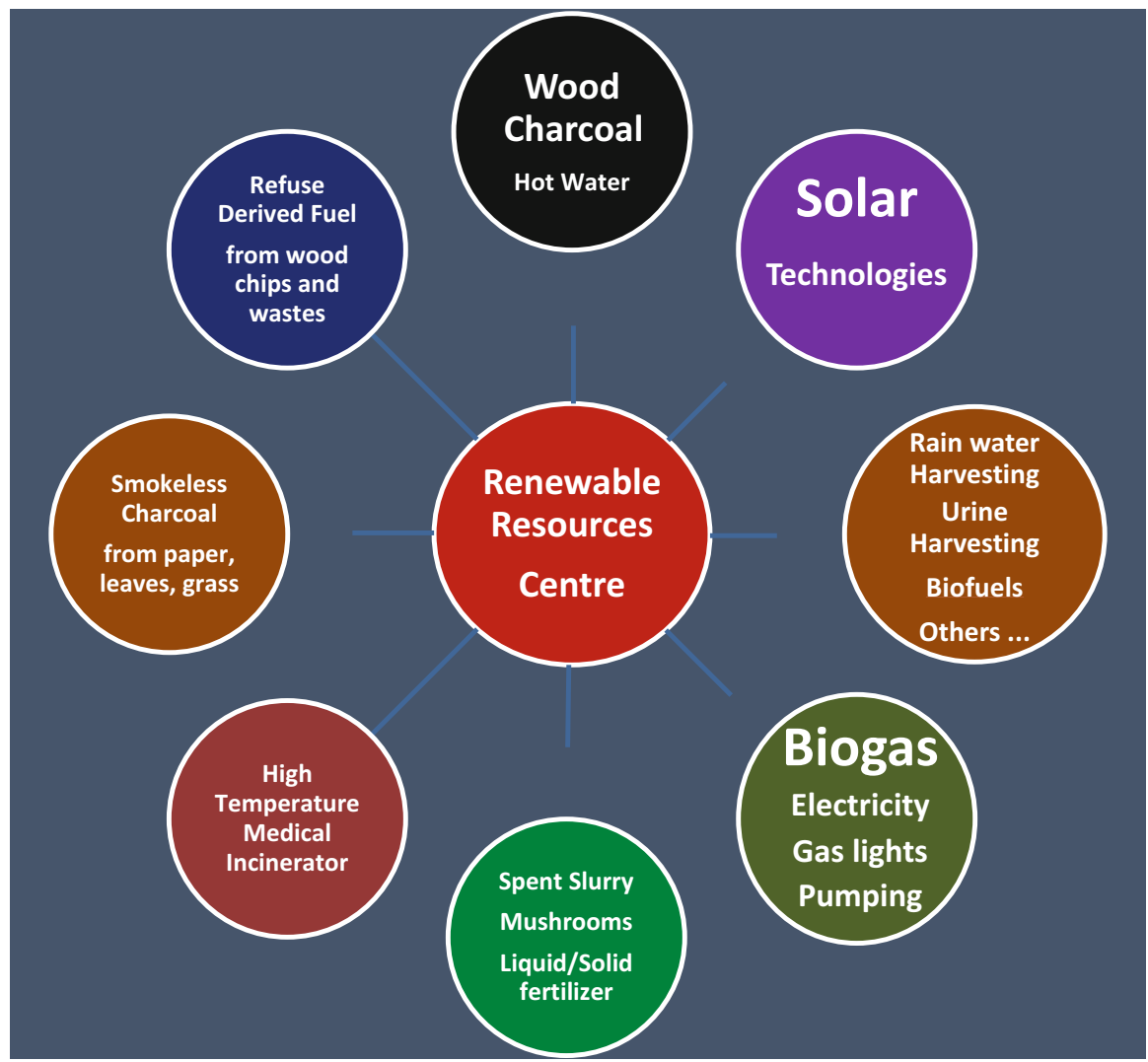

Fig. 2 Various sections at Renewable Resources Centre

(v) Permanent kiln for smokeless charcoal/biochar production.

(vi) Charcoal Kiln (a design adopted from Kenyan/Ethiopian technology) to produce charcoal within $24 \mathrm{~h}$ from fallen and cut trees.

(vii) Home composter for low-scale production of compost at house and farm unit.

(viii) Portable refuse-derived fuel unit.

(ix) A demonstration plot land set aside opposite the biogas section for demonstrating some of the products for agricultural production. Here, various fieldbased experiments are carried out.

(x) Rainwater harvesting for ensuring the availability of water all year round with elementary and useful technology.

It is expected that the RRC will become a center of attraction for people to get trained on "Waste to Wealth" and "Waste to Energy" technologies. The center will benefit Nigerian communities as well as other developing economies through "Town and Gown" meet. 


\section{Activities and Climate Change Adaptive Technologies at Various Sections of the Center}

Training Hall: About 30 people can comfortably sit and receive training. The room is equipped with two air conditioners, a PowerPoint projection, and a cupboard to display some standard books for the trainees to use. The target training participants include interested individuals, small and big scale farmers, members of cooperative society, students, and retirees (Fig. 3a).

\section{Biogas Generation and Compression}

There are two types of biogas digesters: One is $8 \mathrm{~m}^{3}$ capacity, flexible, and a product of PVC which can expand as the gas is generated (Fig. 4a). This kind of digester is suitable for larger families or establishments that need more gas for consumption. The other is a unique floating dome variety; the capacity can vary from 1 to $10 \mathrm{~m}^{3}$ or more, built from readily available water storage tanks from the local markets. They are affordable for households and have the potential for promotion at community levels to individual families. The biogas plants are designed to use dairy waste, poultry waste, piggery waste, or food waste from kitchens. Available end products from this section are biogas lamp, biogas compressor, biogas- multipurpose
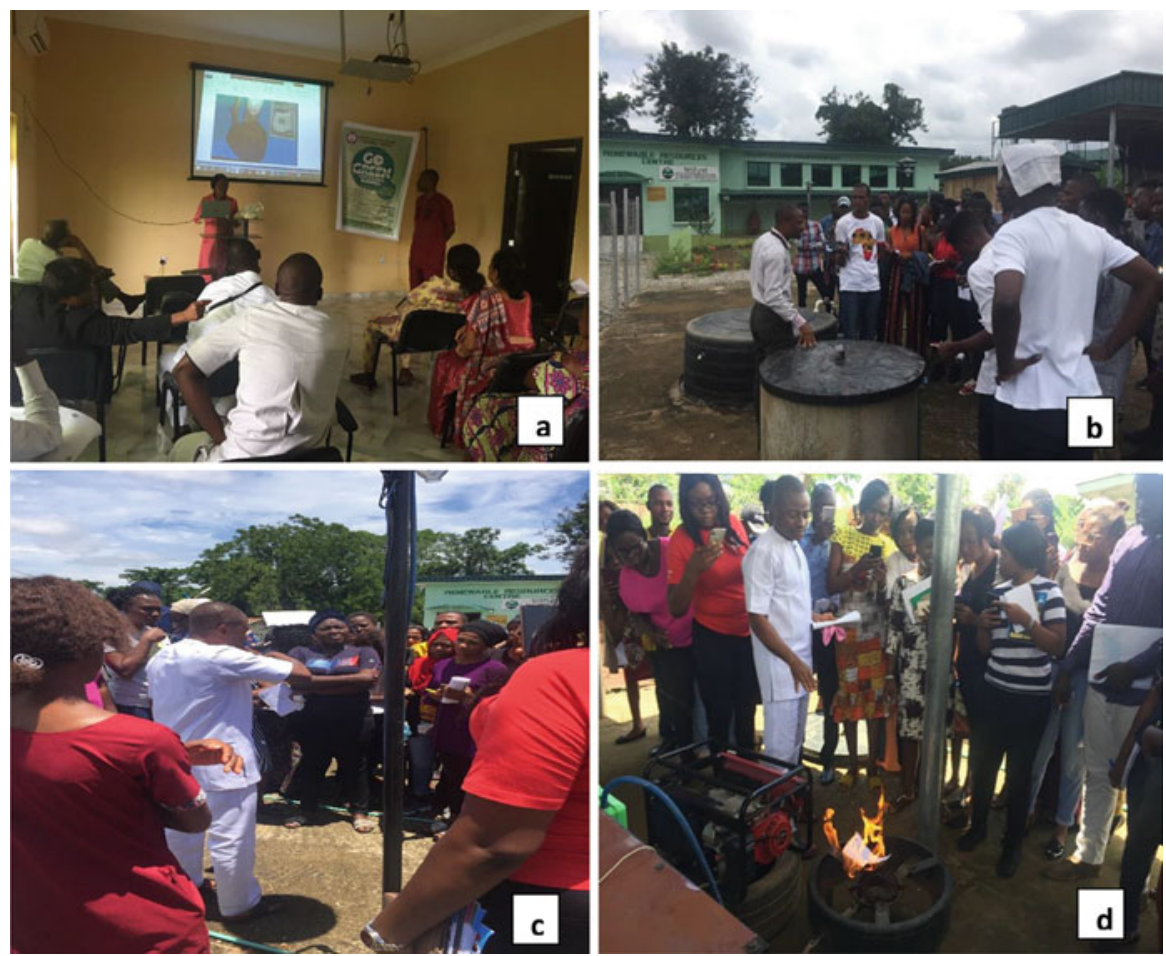

Fig. 3 Training activities at the center $(\mathbf{a}, \mathbf{b}, \mathbf{c}, \mathbf{d})$ 


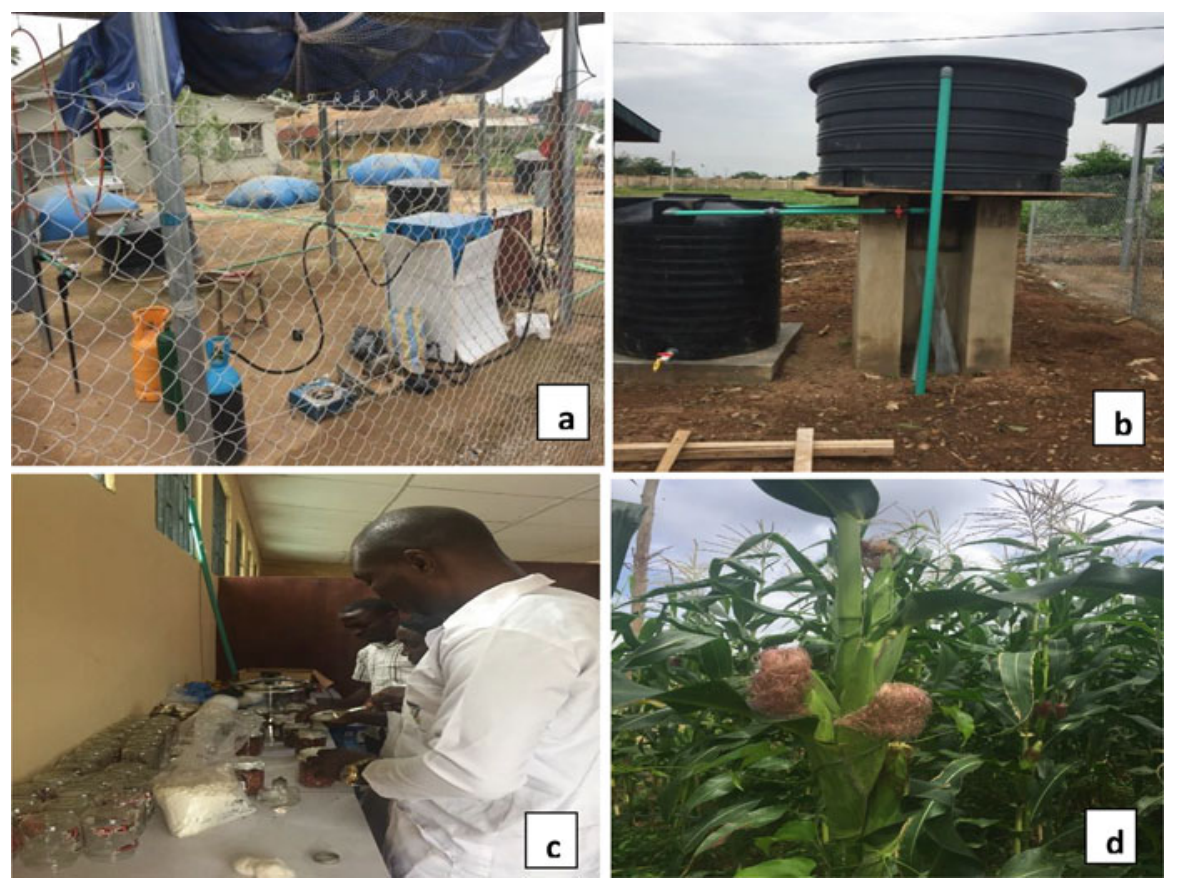

Fig. 4 Various components at RRC: (a) biogas compression unit; (b) effluent treatment filtration tank; (c) mushroom spun production room and (d) con-planted on treated effluent with many fruits on a stem

electricity generator, space heater, cooking stoves, and liquid and solid fertilizers produced from an effluent treatment filtration tank (Fig. 4b). The lamp is suitable for lighting an area without greenhouse gas emissions while the biogas cleaning unit is used to increase the percentage of methane. There is a kit that can be fixed to a household petrol-driven generator so that it can be adjusted to use petrol, natural gas, or biogas. The biosolids obtained after proper filtration are made into a very rich organic fertilizer that is used for mushroom cultivation (Fig. 4c) and raising crops at the demonstration plot (Fig. 4d). Besides, the space heater is used for warming young chickens in the poultry pens. At the same time, biogas fuel conversion kits and the portable cylinder are being tested to run vehicles, including cars, motorcycles, and tricycle, on biogas production from organic waste.

\section{Mushroom Cultivation}

A mushroom hut was built using materials ideal to maintain the required low temperature and humidity. In this hut, mushrooms will be grown from waste materials such as spent slurry, sawdust, etc. Also, bottles of spun (mushroom seedlings) of various tasty varieties are produced for household cultivation. 


\section{Wood Charcoal Kiln}

A lot of trees fall due to heavy breeze and storms, and they are moved out by needy people for cooking purposes in an environmentally unfriendly manner that exacerbates climate change effects. A modern kiln available at the center can convert wood and cutoff trees to quality charcoal good commercial value (Fig. 5f). The furnace

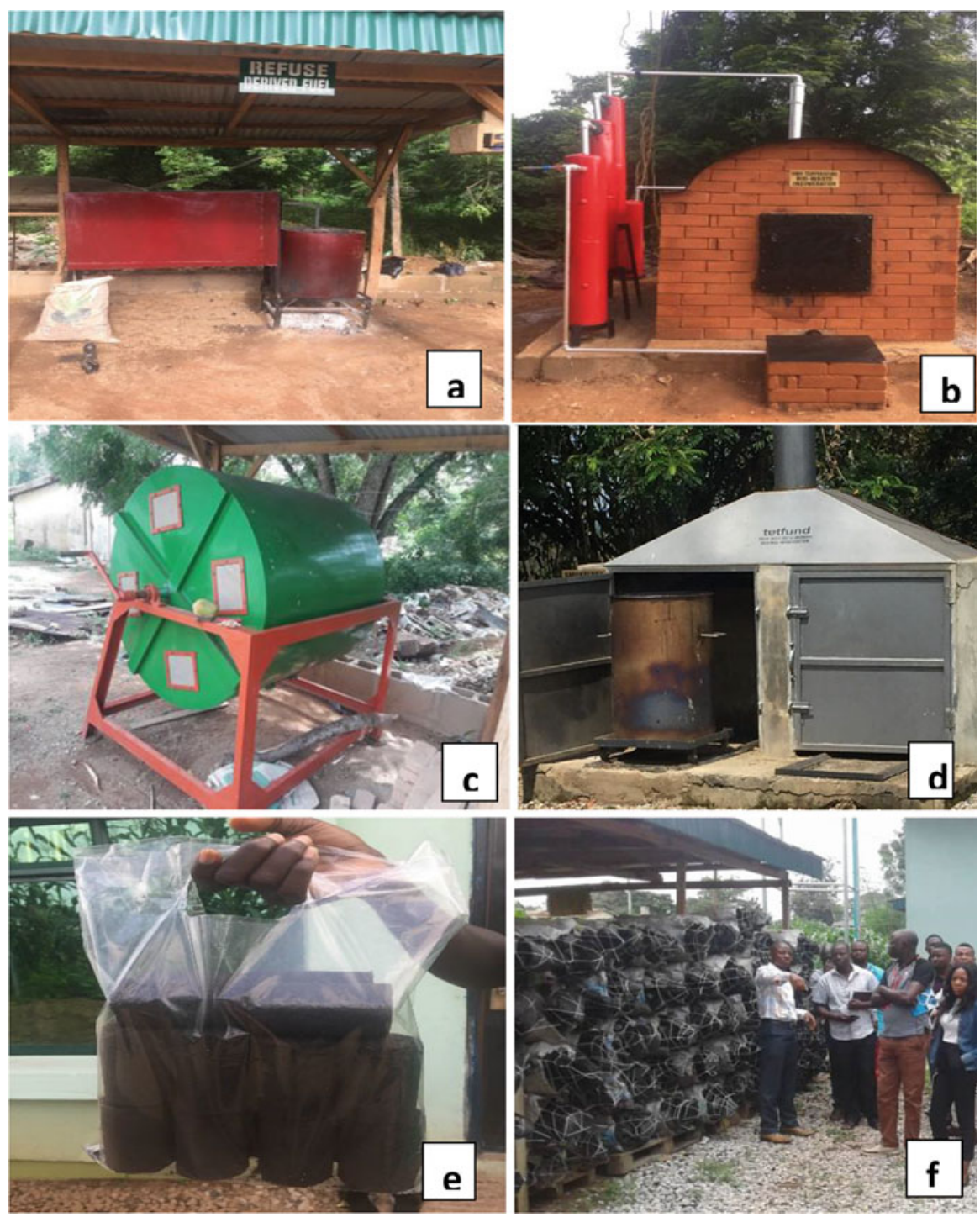

Fig. 5 Other climate change adaptive technologies at RRC: (a) RDF plant; (b) smoke-free incinerator; (c) household composter; (d) smokeless charcoal kiln; (e) smokeless charcoal pellets; (f) wood charcoal 
eliminates the traditional rural practice of digging holes all around and burning the wood openly, thus releasing greenhouse gases. In a 48-h cycle, 15-25 bags of charcoal are produced. Apart from a brick-made kiln for wood charcoal, there is another metal type (Fig. 5d) that converts light putrescible wastes to smokeless charcoal that is very popular in most of the western countries. By definition, when the charcoal is burned, no smoke is generated in the kitchen. This technology converts agroforestry residues: grass clippings, fallen leaves, maize stalks, lawn mowing, paper, sawdust, and other wastes from farms to biochar useful for farm input, wastewater treatment domestic cooking (Chang et al. 2011), warming house during cold weather, septic tank treatment, and others. The end product is in the form of charcoal powder (biochar) which is pelletized using a hand-operated extruder after some binder is added. Rejects and dust in the wood charcoal kiln are charged with treated effluent from the biogas digesters to produce nutrient-rich biochar that is sold to farmers as cheap fertilizer. The center also provides biocide-embedded smokeless charcoal for malarial control and energy for domestic cooking, at the same time (Fig. 5e). In the charcoal production process, a lot of heat is lost to the environment. The technology incorporated piped water into the furnace, whereby the temperature can be used to produce hot water. The poultry on the farm uses a lot of hot water, and it is a benefit.

According to Ana et al. (2013), global warming and its consequences on climate are among the problems posed by overdependence on fossil oil reserves. These drawbacks require exploring alternative energy sources such as biofuels that are environmentally friendly and renewable. Meanwhile, Bouros and Samiou (2001), Da Costa et al. (2004), and (Karve 2006) have earlier linked gaseous emissions from wood charcoal fires especially in an indoor environment to the incidence of many respiratory illnesses. The use of smokeless charcoal can reduce indoor air pollution, diseases, and gross environmental problems, arising from solid waste mismanagement while creating access to business opportunities for women and disadvantaged groups.

\section{High-Temperature Incinerator}

For managing healthcare wastes, a recommended method is incineration operated at $1200^{\circ} \mathrm{C}$ (Fig. 5b). However, none of the incinerators utilized in developing countries meets that requirement as they generally produce temperatures below $600{ }^{\circ} \mathrm{C}$. World Bank tried to promote an incubator designed in the UK (De Montfort). Even this model is not able to maintain such an extreme temperature. Through locally developed and improved technology, the center designed an incinerator that uses heat generated from syngas. The heat is injected back into the incineration chamber to increase its temperature to around $800-1000^{\circ} \mathrm{C}$. The unit can also be used to handle pyrolysis of scrap tires and some types of e-waste which is an emerging global environmental health importance, as these wastes have become one of the fastestgrowing waste types in the world (Sharma et al. 2012). The available end products in this section are carbon black and black oil that are generated from the smoke that might contribute to global warming as well as metal scrap salvaged from scrap tires. The distinctiveness of the plant is that: the unit is entirely covered to reduce the 
emission of GHGs, heat produced during the operation, in form of syngas, is used to replenish the furnace temperature, and the smoke generated is converted to diesel after some treatment. The unit can be operated safely at any convenient place since there is no pollution of the environment. Additionally, materials used in constructing the unit are locally available while the unit powers itself to treat hazardous wastes, hospital waste, and agricultural wastes.

\section{Refuse Derived Fuel (RDF) Plant}

This compartment uses small wood chips (paper or any dry waste) and charcoal which on heating produce a black oil and, on further heating, produce a gas (syngas). This gas can be stored in a bag or cylinder and may be used to run a household generator to produce electricity, similar to biogas. The gas can also be used directly such as biogas for cooking at the household or institutional level. In this section, the end products are syngas and charcoal that emit very little smoke. This new innovative technology (Fig. 5a) has been developed to generate syngas from all types of combustible solid wastes and use the gas to run generators for electricity. In addition to health safety and environmental protection, this technology will be of great benefit to the rural and peri-urban populations who may want to develop small or medium scale entrepreneurship with low investment and very little skills. It does not need electricity or any sophisticated mechanical devices.

Gasification- and pyrolysis-related processes are usually confused with one another. Zhou et al. (2008) identified the major difference between the two methods as the gasification occurs in the presence of oxygen. On the other hand, pyrolysis does not require oxygen or air during its process. However, gases and liquids produced in the pyrolysis and gasification processes have high contents of carbon monoxide $(\mathrm{CO})$ and hydrogen gas $\left(\mathrm{H}_{2}\right)$ that can be a good source of syngas. The syngas is used for the production of methanol and ethanol or $\mathrm{H}_{2}$ used in fuel cells (Baumlin et al. 2006). For example, gases with the main benefit of pyrolysis is that it offers clean heat, which is needed to develop cooking technology with lower indoor pollution by smoke than is typically generated during the burning of biomass (Bailis et al. 2005). Also, the by-product is smokeless briquette charcoal, because, during carbonization, its smoke disappears.

\section{Home Composter}

This unit was designed for low-scale production of compost at houses and farm units (Fig. 5c).

The RRC is intended to be operated on a sustainable basis through various sources of revenue generation, including the following:

(a) Consultancies and turnkey projects for public and government bodies on the technologies developed at the center (fertilizer, biogas, charcoal, smokeless charcoal, etc.)

(b) Sale of products such as charcoal, biogas kits, mushrooms, maggots, liquid and solid organic fertilizers, black oil, carbon black, and organically grown produce from the demonstration plot 
(c) "Science Tourism" and education visits of schools, and the public

(d) Assisting researchers through the use of locally fabricated equipment

(e) Training programs (short-term) and hands-on training

(f) Donors and philanthropists

(g) University support for innovative researches and grants

(h) Hospital waste management services

(i) Compression of gas into cylinders for domestic uses

\section{From Climate Change to Community Change: Lesson from Kube-Atenda, Nigeria}

This scheme is community-led waste management for reducing greenhouse gas emission and mitigating climate change effects at Kube Atenda, Ibadan, Nigeria. The project was carried out under the Climate Impacts Research Capacity and Leadership Enhancement in Sub-Saharan Africa (CIRCLE) program and executed by the UK's Department for International Development (DFID), in collaboration with the Association of Commonwealth (ACU) and African Academy of Sciences (AAS). Transformative adaptation and sustainable responses to climate change (Fig. 6a-d) that were adopted included: a large scale stakeholders' workshop that comprised community people (the users), local council representatives, private practitioners, and selected people from the general public; creation of a sorting center/recycling kiosks for recyclable buyback arrangement and entrepreneurship opportunities; Waste-to-Electricity through a newly invented pyrolytic chamber for converting accumulated waste to energy and useful by-products; developing market links for recyclables between the community's buyback center and resource recovery centers; developing effective communication among all the stakeholders and decision-makers; and instituting monitoring and evaluation for progress control through the involvement of Department of Community Development Inspectorate (CDI) at Ibadan Northeast LGA (local council). Specifically, this project focused on behavioral change of the community member toward solid waste management practices that will ensure wealth creation and development, using the $4 \mathrm{R}$ concept (Reduce, reuse, recycle, and recover).

Before this uptake activity, the community had been faced with a big challenge of solid waste management. There were heaps of waste around the community while people were disposing of their garbage on illegal dumps, in open spaces, and in water bodies, or burning them openly in an environmentally friendly manner. The training component of the research led to building people's capacity in waste to wealth as the community members were taught on how to sort their solid waste into paper, glass, plastics, and other recyclables for recycling, reuse, and sale at the community buyback center. They were also taught a way to produce organic fertilizer from organic waste and biochar (smokeless charcoal) from agroforestry residues to generate an inexpensive and clean source of energy for domestic cooking. There was a rise within the level of awareness of the consequences of poor solid waste 


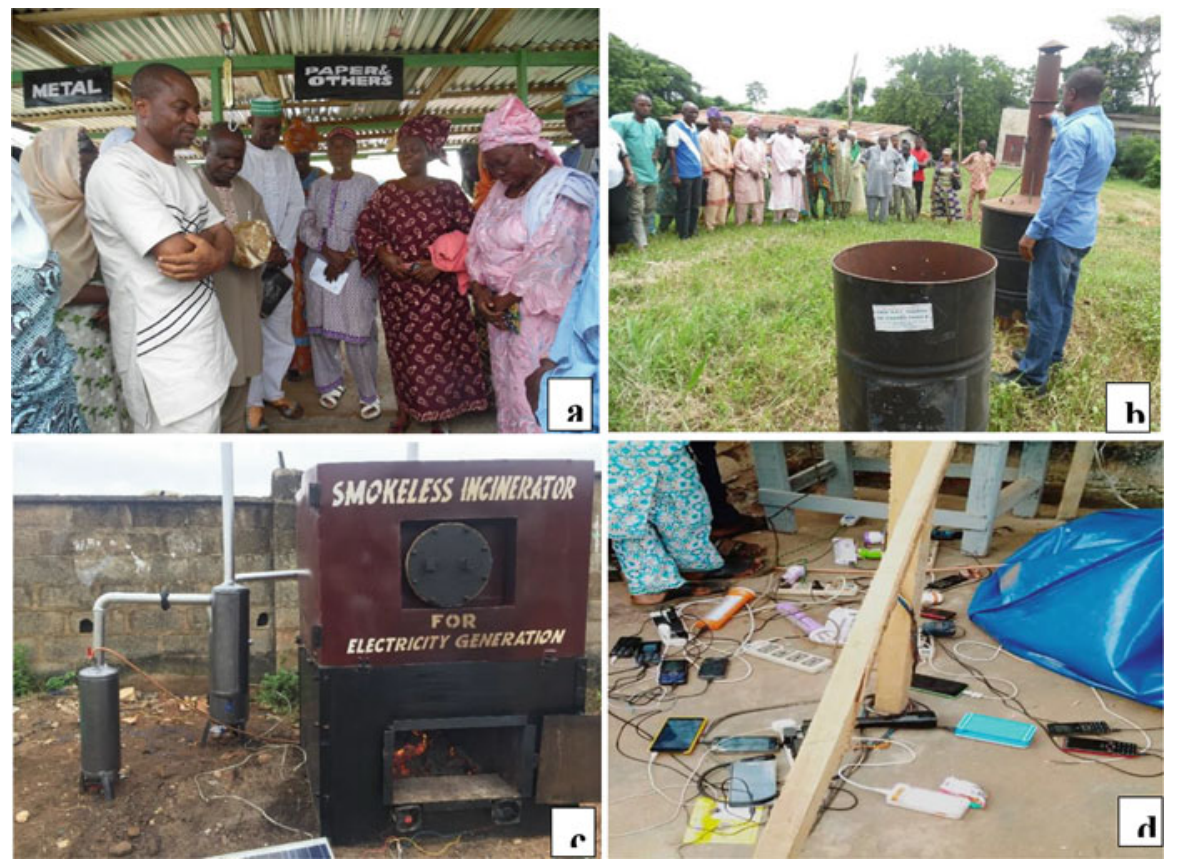

Fig. 6 Climate change mitigation and adaptation initiatives at Kube-Atenda: (a) recycling kiosks for recyclable buyback arrangement, (b) field demonstration on charcoal production, (c) pyrolytic chamber, and (d) phone-charging center

management, such as health hazards, esthetic damage, and other environmental problems in the community.

Moreover, the pyrolytic chamber generates gas that powers a generator for electricity supply and produces black oil from which diesel and kerosene can be distilled. The electricity supplied is used to power a phone-charging center (Fig. 6d) that financially empowers the youths who are managing the center.

The center is now a study area for young- and midcareer researchers and postgraduate students in universities across the country. This project is meeting the people's needs, including economic development, safe environment, poverty reduction, and healthful living. Also, policymakers in the state and across the country will find the uptake and research evidence very useful in their planning and activities.

\section{Integrating Waste Picking at Dumpsites into a Value-Added Chain in Nigeria}

Old dumpsites contain a high proportion of recyclables, including minerals and metallic components including e-waste, ferrous scrap, aluminum, and copper cable that could be salvaged and reprocessed. Also, the highly calorific waste components 
(wood, plastics or paper, textiles, and paper) could be used to generate energy (Bachmann and Cordes 2007). Recycling of these wastes has the potential to create jobs for waste pickers, by promoting entrepreneurs to establish waste recovery facilities at dumpsites. Adding waste into the value-added chain formally will reduce the quantity of wastes disposed to landfill sites and improve the practices that endanger the health and safety of waste pickers, at landfills/dumpsites.

In many developed countries such as those within the European Union, policies of reduction, reuse, and diversion of wastes from dumpsites/landfill are strongly promoted (European Environment Agency 2003). The situation is quite different in Nigeria as the main fractions of wastes generated are recyclables including organic materials, plastics/rubbers, cardboard, metals, and glass bottles (Ojolo 2004). These wastes are stored and transported directly to some designated dumpsites where they are burnt eventually. This practice has potential impacts on the health and hygiene of people in the neighborhood and the esthetic nature of the environment.

Zerbock (2003) noted that waste dumping is the well-liked method of putting off solid waste rather than sending wastes to landfills in most African countries. Wastes are solely dumped in low-lying areas without engineered measures to prevent environmental pollution. In open dumps, there is no consideration for leachate and gas management. Also, operational standards, such as registration of users, control of the number of tipping fronts, or compaction of waste, are few, if not absent. This method is neither hygienic nor safe as waste is tipped haphazardly. However, African countries have a minimal choice because of their low financial capacity and lopsided institutional arrangements. The responsibility of waste disposal is vested in local governments which are weak and cannot usually raise money to construct sanitary landfills. Some countries use semicontrolled landfills whereby wastes are dumped uncontrollably at designated dumpsites without covering with topsoil to prevent odor and rodent nuisance. In this kind of landfill, various wastes such as municipal, industrial, or clinical/hospital wastes are dumped, not following internationally approved best practices.

\section{Waste-Picking Activities at the Dumpsites: A Case Study of Ibadan, Nigeria}

Through Focus Group Discussion (FGD) sessions and observation checklist, the authors assess the dynamic of waste picking at the four designated dumpsites in Ibadan, Nigeria. The dumpsites included in the survey were: Ajaganka, Awotan, Lapite, and Afonfura. For the FGD, questions were structured to cover the following major activities: population and category of workers, business activities, method of business apprentice, factors that affect the operation, including technical, environmental, social, and economic factors, and perception of scavengers on business optimization and improvement. 


\section{Category of Workers and Prices of Items}

When asked about the number of scavengers at each dumpsite, the following responses were gathered: Ajaganka - 20 (17 males and 3 females); Awotan - 20 (15 males and 5 females); Lapite - 5 (4 males and 1 female); and Afonfura - 28 (18 females and 10 males). There were more males than females except at Afofunra where 18 females were found as against 10 males. As per the year of experience, the age ranged between 3 and 20 years. According to the discussants, there was a competitive demand for recyclables. They sold the recyclables to the manufacturers who came to buy them directly from the sites. Each recyclable had a fixed price and the unit of measurement was either in $\mathrm{kg}$, ton, or dozen, depending on the types of recyclables. The prices of the recyclables were given thus: tin (including milk can) - 20/kg; pet bottles - 30/kg; glass bottles - 20/dozens (depends on sizes and color); plastic scrap - 30/kg; nylon - 12/kg; aluminum (including some beverage cans) - 50/kg; copper (wire) - 800/kg; brass $400 / \mathrm{kg}$; steel - 30/kg; zinc - 50/kg; stainless metal $-80 / \mathrm{kg}$; electronics (including computer panel) $-800 / \mathrm{kg}$; sacs - 60/dozen; carpet $-20 / \mathrm{kg}$; and Rug $-10 / \mathrm{kg}$. The prices of the recyclables depend on demand from industrialists who use recyclables as potential materials for manufacturing. Economic aspects of salvaging recyclables from dumpsites have been widely reviewed (Rettenberger 1995; Van der Zee et al. 2004). In these studies, possible costs and benefits that may be obtained from using dumpsite as material recovery centers were outlined on a large scale. Some of the benefits listed were revenue from recycled materials and saving land space at dumpsites to increase their life spans. Contrary to this observation, the economic feasibility of landfill mining could not be meticulously addressed by previous studies (Savage et al. 1998; Cossu et al. 1996), and in some studies, such initiatives have been considered nonbeneficial (Cobb and Ruckstuhl 1988; Bryden 2000).

At all the dumpsites, more males were found than females because more physical strength required for the job was attributed to males and that females were usually discouraged by the stigmatization attached to the work by the people. The discussants were satisfied with their job because of their achievements and sustainable daily income from the sale of recyclables.

\section{Method of Business Apprenticeship}

The waste pickers could not identify any method of apprenticeship during the discussion. The majority of them joined the business haphazardly; they associated their enrolment into the job with severe financial problems and bankruptcy. Their main plan was to leave the job as soon as they recovered from insolvency. Contrarily, having tasted the good returns from the job, they found it difficult to go, even after they had overcome their financial burdens. The waste pickers said further that the business required little or no capital to start with and the principal instrument required was a picker. They did not register with any government agency or ministry. As such, there was no monitoring from the government or any nongovernment organization. 


\section{Factors That Affect the Operation of Waste Pickers}

Among other things, almost all of the discussants listed the following as significant constraints they faced in the job: lack of proper and controlled tipping that sometimes leads to site congestion and open burning, disturbances from environmental health officers who usually extort money from them, odor and flies from abattoir waste, transportation, lack of business regulation, and fire outbreak. Other constraints cited were sickness (mostly from fever, body pains, whitlow, and laceration) as well as smoke, and flies and odor problems. When asked about steps taken for their preventive measures, many of them used self-medication. Besides, almost all of the discussants did not use Personal Protective Equipment (PPE), claiming that the use of PPE was not convenient to them and that they lacked financial capability to do so. This practice may have a profound effect on their health and well-being. Most of the waste composition studies address environmental and safety issues at dumpsites (Hogland et al. 1995; Cossu et al. 1995; Zhao et al. 2007; Prechthai et al. 2008) and show that the practices at municipal dumpsites are not effective. Many of the dumpsites have no fence, allowing unregulated access to the site and dumping of restricted materials, such as toxic wastes. Additionally, owing to the poor control of activities at dumpsites, medical and hazardous wastes end up at those dumpsites even though there are no particular dumping areas for such wastes in the city.

\section{Perception of the Waste Pickers on Business Optimization and Improvement}

Suggestions on how the job can be improved were sought from the waste pickers. Very few of them that responded said the government should absorb them into the civil service, give them proper training, especially on waste recycling, and support them with necessary facilities. Also, the discussants thought that the marketing of the recyclables could be improved significantly if the government could purchase the recyclables from them and act as a wholesaler. According to Mocker et al. (2009), due to the increasing scarcity and costs of different raw materials, the recovery of recyclables from dumpsites as a source for raw materials is rising steadily.

\section{Quantity of Waste Picking Per Month at the Four Dumpsites}

The output, in terms of quantities of recyclables salvaged per month for the four sites, is represented in Fig. 7. The most purchased component was plastics, followed by paper and organic waste. Rugs and electronics were found at the lowest proportions. The thin film and organic waste were not sorted, though they equally had high recycling potentials. According to the participants, "Organic waste was messy and very difficult to deal with"; it could not be stored without much problem, especially those related to odor and flies nuisance. Besides, thin film such as pure water sachets remained very common; it could be found anywhere and everywhere without stress, leading to its low offered price. Waste components such as disused mattresses and packaging plastic foams had very little or no secondhand values; they could instead be reused than recycled. Also, an individual waste picker was assigned 


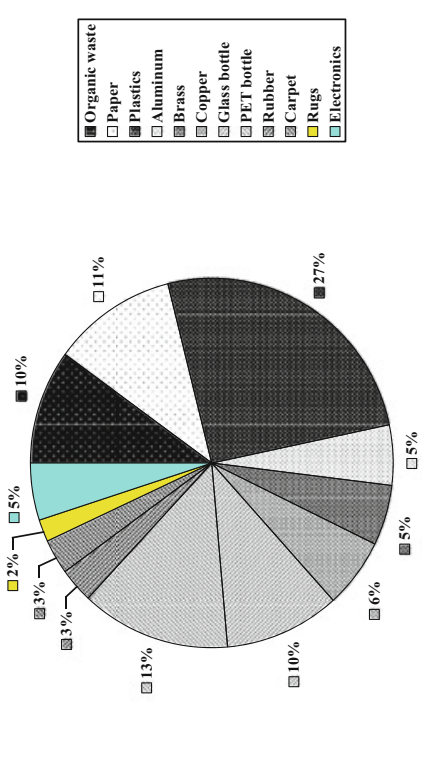


with a specific type of recyclable, and the number of waste pickers working at each site reflected the quantities of recyclables obtainable at such site.

\section{Conclusion}

The rate at which climate change affects developing economies has called for urgent measures to cope with unexpected climate phenomena. Climate change effects threaten to exacerbate existing vulnerabilities and pose unprecedented challenges and opportunities for people in this part of the world. Based on these premises, this chapter describes grassroots projects and the diversity of approaches to climate change management. Apart from the results of research and field projects, this section also showcases practice-oriented procedures, case studies, innovative local adaptation practices as well as barriers and limits to climate change management. The contents are expected to foster resilience and capacity building among communities in developing countries.

\section{References}

Ana PGP, Betania HL, Rubens MF (2013) Application of biomass to hydrogen and syngas production. Chem Eng Trans 32:589-594

Ashton W, Chertow M, Shenoy M (2009) Industrial ecology - developing systemic solutions to climate change and other environmental challenges in Indian industry. Sustain Tomorrow 4(4): 48-55

Bachmann M, Cordes M (2007) Das Rohstoffpotential von Altdeponien aus wirtschaftlicher Sicht (the raw material potential of old dumpsites). In: Wiemer K, Kern M (eds) Bio- und Sekundärrohstoffverwertung II. Witzenhausen-Institut für Abfall, Umwelt und Energie GmbH, Witzenhausen, pp 857-869

Bailis R, Ezzati M, Kammen DM (2005) Mortality and greenhouse gas impacts of biomass and petroleum energy futures in Africa. Science 308:98-103

Baumlin S, Broust F, Bazer-Bachi F et al (2006) Production of hydrogen by lignins fast pyrolysis. Int J Hydrogen Energy 31:2179-2192

Bouros D, Samiou MF (2001) Short-term effects of wood smoke exposure on the respiratory system among charcoal production workers. CODEN CHETBF 119(4):1260-1265

Bryden G (2000) Factors influencing the feasibility of wood products in landfill waste recovery for beneficial re-use. In: Proceedings of the 2000 TAAPI international environmental conference \& exhibition, Denver, pp 527-535

Chang ACC, Chang HF, Lin FJ et al (2011) Biomass gasification for hydrogen production. Int J Hydrog Energy 36:14252-14260

Chertow MR (2009) The ecology of recycling. The UN Chronicle online, special climate change issue 2009

Chertow MR, Lombardi DR (2005) Quantifying economic and environmental benefits of co-located firms. Environ Sci Technol 39(17):6535-6541

Cobb CE, Ruckstuhl K (1988). Mining and reclaiming existing sanitary landfills. In: Proceedings of the national waste processing conference, Detroit, pp 145-151

Cossu R, Motzo GM, Laudadio M (1995) Preliminary study for a landfill mining project in Sardinia. In: Proceedings Sardinia 95, fifth international landfill symposium, Cagliari, pp 841-850

Cossu R, Hogland W, Salerni E (1996) Landfill mining in Europe and the USA. ISWA Tear Book, pp 107-114 
Da Costa JL, Navarro A, Neves JB et al (2004) Household wood and charcoal smoke increases the risk of otitis media in childhood in Maputo. Int J Epidemiol 33(3):573-578

Dehoust et al (2005) Status report on the waste sector's contribution to climate protection and possible potentials. Commissioned by the German Federal Environmental Agency, Berlin

European Environment Agency (EEA) (2003) Europe's environment: the third assessment. Environmental assessment report no 10, vol 7. EEA, Copenhagen, pp 151-164

Fauzul RS, Viradin Y (2011) Community participation as community-based integrated waste management. International Journal of Academic Research 3(2):434-441

Gwatkin DR, Rutstein S, Johnson K et al (2000) A. Socio-economic differences in health, nutrition, and population. HNP/poverty thematic group. World Bank, Washington, DC

Hammed TB, Sridhar MKC, Olaseha IO et al (2012) Community perceptions on a governmentprovided integrated-waste recycling plant: experience from Ibadan, Nigeria. Int J Sci Soc 3(3): $145-158$

Hammed TB, Shem OW, Yacob M et al (2018) Improving knowledge and practices of mitigating green house gas emission through waste recycling in a community, Ibadan, Nigeria. Waste Manag 81:22-32

Harris P (1999) On charcoal. Interdiscip Sci Rev 24:301-306

Hogland W, Jagodzinski K, Meijer JE (1995) Landfill mining tests in Sweden. In: Proceedings Sardinia '95, fifth international landfill symposium, Cagliari, pp 783-794

IPCC (2006) IPCC guidelines for national greenhouse gas inventories. In: Eggleston HS, Buendia L, Miwa et al (eds) Prepared by the national greenhouse gas inventories programme. IGES, Japan

Karve AD (2006) Briquette charcoal from sugarcane trash. Drupal, Belgium

McDonald S, Ball R (1998) Public participation in plastics recycling schemes. Resour Conserv Recycl 22:123-141

Mocker M, Fricke K, Löh I (2009) Urban Mining - Rohstoffe der Zukunft (Urban mining - raw materials for the future). Müll und Abfall - Fachzeitschrift für Abfall- und Ressourcenwirtschaft 42(10):492-501

Ojolo SJ (2004) Conversion of municipal solid wastes into medium grade fuel and industrial raw materials in Lagos Island. $\mathrm{PhD}$ thesis, University of Ibadan

Oluwole O, Otaniyi OO, Olopade CO (2012) Indoor air pollution from biomass fuels: a major health hazard in developing countries. J Public Health 20. https://doi.org/10.1007/s10389-0120511-1

Paula U, Elizabeth R (2008) Factors influencing households' participation in recycling. Waste Manag Res 26(2):140-146

Prechthai T, Padmasri M, Visvanathan C (2008) Quality assessment of mined MSW from an open dumpsite for recycling potential. Resour Conserv Recycl 53:70-78

Rettenberger G (1995) Results from a landfill mining demonstration project. In: Proceedings Sardinia '95, fifth international landfill symposium, Cagliari, Italy, pp 827-840

Salvi S, Barnes P (2010) Is exposure to biomass smoke the biggest risk factor for COPD globally? Chest 138(1):3-5

Savage GM, Diaz LF, Golueke GC (1998) Guidance in landfilling waste in economically developing countries. US Environmental Protection Agency, Cincinnati, p 467

Sharma P, Fulekar MH, Pathak B (2012) E-waste- a challenge for tomorrow. Res J of Rec Sci (3):86-93

Smith AK, Brown S, Ogilvie K et al (2001) Waste management options and climate change. Final Report ED21158R4.1 to the European Commission, DG Environment, AEA Technology, Oxfordshire, $205 \mathrm{pp}$

Sridhar MKC, Hammed TB, Anthony O (eds) (2016) Entrepreneurship in waste recycling. Book Builders, Ibadan. $750 \mathrm{pp}$

The Guardian (2015) UNHabitat sets seven-point agenda to transform Nigerian cities. https:// guardian.ng/property/unhabitat-sets-seven-point-agenda-to-transform-nigerian-cities/. Accessed $25 \mathrm{Feb} 2020$ 
Tucker P, Lamont J, Murray G (1998) Predicting recycling scheme performance: a process simulation approach. J Environ Manag 53:31-48

UNEP (2010) Waste and climate change: global trends and strategy framework. United Nations Environmental Programme Division of Technology, Industry and Economics, International Environmental Technology Centre, Osaka/Shiga

US Environmental Protection Agency (2006) Solid waste management and greenhouse gases: A life cycle assessment of emissions and sinks, 3rd ed. US Environmental Protection Agency, Washington

Van der Zee DJ, Achterkamp MC, de Visser BJ (2004) Assessing the market opportunities of landfill mining. Waste Manag 24:795-804

Zerbock O (2003) Urban solid waste management: waste reduction in developing nations (written for the requirements of CE 5993 field engineering in the developing world). Michigan Technological University, Houghton, pp 89-105

Zhao Y, Song L, Huang R (2007) Recycling of aged refuse from a closed landfill. Waste Manage Res 25:130-138

Zhou CH, Beltramini JN, Fab YX, LU GQ (2008) Chemoselective catalytic conversion of glycerol as a bio-renewable source to valuable commodity chemicals. Chem Soc Rev 37:527-549

Open Access This chapter is licensed under the terms of the Creative Commons Attribution 4.0 International License (http://creativecommons.org/licenses/by/4.0/), which permits use, sharing, adaptation, distribution and reproduction in any medium or format, as long as you give appropriate credit to the original author(s) and the source, provide a link to the Creative Commons license and indicate if changes were made.

The images or other third party material in this chapter are included in the chapter's Creative Commons license, unless indicated otherwise in a credit line to the material. If material is not included in the chapter's Creative Commons license and your intended use is not permitted by statutory regulation or exceeds the permitted use, you will need to obtain permission directly from the copyright holder.

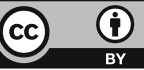

